\title{
The Effects of Bariatric Surgery on Bone and Nephrolithiasis
}

Khashayar Sakhaee, John Poindexter, and Crystal Aguirre

Department of Internal Medicine, Charles \& Jane Pak Center for Mineral Metabolism \& Clinical Research, University of Texas Southwestern Medical Center, Dallas, TX.

Abbreviated Title: Bariatric Surgery

Key Terms: Bariatric surgery, bone disease, kidney stone disease

Word Count: 3,540

\section{Corresponding Author:}

Khashayar Sakhaee, MD

5323 Harry Hines Blvd,

Dallas, TX 75390

(Phone) 214-648-9640

(Fax) 214-648-2526

(Email) khashayar.sakhaee@utsouthwestern.edu 


\begin{abstract}
The impact of bariatric surgery on cardiovascular and diabetic complications associated with an improvement in survival has overshadowed the adverse skeletal health and development of kidney stone disease in this population.

All longitudinal based studies in the literature reporting the incidence of bone fractures or kidney stones following bariatric surgery were reviewed. Moreover, all publications over the past decade which assessed changes in bone mineral density, bone quality, or explored underlying pathophysiologic mechanisms of bone and kidney stone disease were carefully reviewed.

This review provides sufficient data to support that osteoporotic fractures and kidney stone disease are associated with Roux-en-Y gastric bypass surgery. However, due to the limited data available to date, no definitive conclusion could yet be drawn whether sleeve gastrectomy or adjustable gastric banding is associated with bone fractures and kidney stones.

Bariatric surgery has emerged as the most effective and sustained treatment for weight reduction. This treatment modality has been recognized to diminish the risk of cardiovascular morbidity and mortality and ameliorate diabetes mellitus complications. The derangement in mineral metabolism has emerged as a major complication following bariatric surgery.
\end{abstract}




\section{Introduction}

Since the early 1960s, the prevalence of obesity among adults has more than doubled with an increase from 13.4 to $35.7 \%$ in the U.S. ${ }^{1}$. The epidemic of obesity plateaued between 1999 and $2010^{2}$, yet the prevalence of extreme obesity is significantly high as $14.5 \%$ of U.S. adults have a body mass index (BMI) of 35 or greater. Compared with normal weight adults, the cost of health care in this population has been estimated to be significantly high.

Life style modifications and pharmacological treatments have been largely ineffective in treatment of extremely obese subjects. Bariatric surgery has emerged as the most effective treatment modality in promoting weight loss, and reducing morbidities and mortalities ${ }^{3,4}$. As a result, an increasing number of bariatric surgeries have been performed worldwide over the past three decades. In recent years, Roux-en-Y gastric bypass (RYGB) exceeded the number of other procedures including sleeve gastrectomy (SG) and adjustable gastric banding (AGB). However, recent reports have established an increasing use of SG in this population ${ }^{5}$. The impact of bariatric surgery on cardiovascular and diabetic complications accompanied with improvement in survival has overshadowed the adverse skeletal health and development of kidney stones.

\section{Bone Fractures after Bariatric Surgery}

To date, there are limited longitudinal population-based studies available to estimate the incidence of bone fractures in patients following bariatric surgery. In one retrospective cohort study in the United Kingdom, a large number of bariatric surgery patients and matched control subjects were examined ${ }^{6}$. This study did not disclose an increase in fracture risk following surgery compared with obese weight match control subjects. In contrast, population based study from Minnesota $(\mathrm{MN})$ reported that bariatric surgery is associated with a 2.3 fold increase in the risk of first fracture at any site ${ }^{7}$. The cumulative incidence of any new fracture was reported to be $58 \%$ over the 15 year follow-up period. Over $50 \%$ of the fractures reported were spontaneous vertebral fractures. The discrepancy between these two studies could be due to inclusion of predominately AGB patients and a short median interval of follow-up of 2.2 years in the United Kingdom cohort but inclusion of predominately RYGB patients in the MN cohort with a longer mean follow-up of approximately 8.9 years $^{6}$.

Moreover, in a recent study in which 120 uncontrolled diabetics were randomized into intensive lifestyle and medical management alone, or lifestyle and medical management plus RYGB showed the latter cohort had more fractures associated with falls compared with the cohort without RYGB. All fractures occurred in women and nutritional deficiencies were more prevalent in the RYGB group, despite use of nutritional support. Although the results were suggestive, this study was not statistically powered to indicate significance ${ }^{8}$. 


\section{Changes in Bone Mineral Density, Microarchitecture and Strength at the Spine \& the Proximal Hip Following RYGB}

Bone strength is clinically determined by BMD analysis, however additional factors including alteration in microarchitecture, bone turnover, and bone mineralization will change the quality of the bone, which may independently increase the risk of bone fragility fractures.

It has been misconstrued that modern bariatric surgeries will overcome the skeletal complications caused by jejunoileal bypass and biliopancreatic diversions, which were abandoned in the $1980 \mathrm{~s}^{9}$. At present, 12 studies have demonstrated robust changes following RYGB in vertebral and hip BMD ranging from -0.03 to $-12.0 \%$ and 0 to $-11 \%$, respectively ${ }^{10-23}$ (Figure 1a \& 1b).

Although fat mass and changes in fat mass may affect areal bone density measurements by DEXA, some studies have averted this problem by utilizing volumetric bone mineral density. A few studies highlighted the deterioration of volumetric bone mineral density and microarchitecture following bariatric surgery ${ }^{16,20,24}$. In a recent one-year longitudinal study of RYGB patients, bone density using DXA and volumetric BMD with quantitative computed tomography (QCT) showed no change in BMD at the proximal hip using QCT compared with matched obese subjects ${ }^{16}$. This finding indicates that the decreases in BMD using DXA is influenced by high fat mass. In an extension of this study for 24 months it was shown that these changes were associated with alterations in microarchitecture and bone strength using highresolution peripheral QCT (HR-pQCT $)^{24}$. The microarchiteratural changes were accompanied by significant trabecular involvement at the radius and a prominent increase in cortical porosity at the tibia ${ }^{24}$. In addition, bone strength, assessed by microfinite element analysis used to estimate failure load was significantly lower at both the radius and tibia in RYGB patients compared to the obese-controls ${ }^{24}$. The changes in the cortical bone property of the tibia were consistent with a previous study suggesting similar changes following bariatric surgery ${ }^{20}$.

\section{Changes in Bone Mineral Density at Spine \& Proximal Hip Following SG \& AGB}

With an increasing trend to perform SG, concern has been aroused towards the development of bone loss in this population ${ }^{25,26}$. The clinical experiences with BMD changes following SG and AGB have been very limited. The results of the three reported studies in literature have been inconsistent, two studies demonstrated BMD changes at the spine ranging from -1.2 to $-4.6 \%$ ${ }^{13,22}$. On the contrary, one study showed an increase of BMD of $+7.9 \%$ one year following SG procedure $^{23}$. Two studies have evaluated changes in hip BMD after SG found that SG led to 
significant loss of hip BMD ${ }^{13,22}$. Due to the small size of these studies no definitive conclusion could be made to define these discrepant results.

\section{Pathophysiologic Mechanisms of Bone Loss Following Bariatric Surgery}

Pathophysiologic mechanisms of bone loss following bariatric surgery are complex and diverse including alterations in mechanical unloading on a skeleton, defective gastric acid secretion, derangements in calcium, calciotropic hormone metabolisms and changes in gastrointestinal peptide metabolism.

\section{Role of Mechanical Unloading on a Skeleton}

Mechanical loading, under normal physiological conditions, participates in the principal role of maintaining bone mass, bone strength, and bone size ${ }^{27}$. Clinical studies exploring the effect of weight loss on BMD following bariatric surgery have been controversial. A few studies demonstrated a direct correlation between weight loss and fall in BMD at weight bearing skeletal sites including the proximal hip ${ }^{15,17,18}$. However, in one recent study, bone loss at both the axial and appendicular skeleton was reported to persist for 24 months following RYGB despite stabilization of weight ${ }^{24}$.

The underlying molecular mechanism of skeletal unloading has been linked to up-regulation of the mRNA of sclerostin $(\mathrm{SOST})^{28}$. Sclerostin is a protein produced principally by osteocytes which possess mechanoreceptors which convert the mechanical signals into biological signals ${ }^{28}$. Sclerostin produced by osteocytes inhibits osteoblastic cell differentiation and function by inhibiting Wnt/beta-catenin ${ }^{29}$. In addition, sclerostin stimulates osteoclastic differentiation and activity mediated by receptor activator of nuclear factor kappa B [RANKL] and inhibition of osteoprotegerin $(\mathrm{OPG})^{30}$.

The potential role of sclerostin and its association with bone loss has been recently shown in one study of 90 pre-menopausal women following RYGB and SG procedures ${ }^{31}$. This study demonstrated rapid and sustained increase of sclerostin level associated with increased bone turnover markers and fall of BMD in this population. With multiple logistic models using receiver operating characteristics (ROC) analysis, the effect of changes of various variables of bone loss in the absence and presence of sclerostin were evaluated. Sclerostin provided the highest predicted value in the percentage of bone loss ${ }^{31}$.

Role of Defective Gastric-acid Secretion and its Contribution to Impaired Calcium Absorption 
Multiple factors including dietary changes, impaired gastric acid secretion, exclusion of duodenum, fast transit time, intestinal fat malabsorption, and vitamin D deficiency all contribute to low intestinal calcium absorption in this population. Intestinal calcium absorption is affected by gastric $\mathrm{pH}$, whereby an acidic $\mathrm{pH}$ enhances intestinal calcium absorption. A few studies have addressed intestinal calcium absorption, but with conflicting results ${ }^{32,33}$. In a very recent study following RYGB, despite normal vitamin D status, intestinal calcium absorption using doublestable calcium isotopes was significantly decreased. This decline in intestinal calcium absorption was associated with a significant fall in 24-hour urine calcium excretion, and significant rise in serum $\mathrm{PTH}^{32}$. However, in another study intestinal calcium absorption was shown to fall but remained within normal range following $\mathrm{RYGB}^{33}$.

Both the dissolution of the food-calcium complexes (e.g. milk) and the solubility of calcium salts in an environment simulating gastric juice are highly dependent on an acidic $\mathrm{pH}^{33}$. To date, no human studies have alluded to whether bariatric surgery will influence gastric $\mathrm{pH}$. In a recent animal study, changes in gastric $\mathrm{pH}$ were examined in RYGB treated rats and sham operated control rats. RYGB surgery resulted in a significant rise in gastric $\mathrm{pH}$, which was also associated with lower bone volume and strength as analyzed by microcomputed tomography ${ }^{34}$. This study in part highlights the importance of impaired gastric secretions in the development of bone disease $^{34}$.

\section{Role of the Calciotropic Hormone Metabolism}

The derangement in calciotropic hormone metabolism has been described in obese subjects before bariatric surgery. Elevated serum parathyroid hormone (PTH) in severely obese subjects compared with non-obese subjects has been shown to decline with weight $\operatorname{loss}^{35}$. Moreover, obese individuals suffer from vitamin D deficiency. The derangement in vitamin D metabolism has been linked to redistribution of vitamin D into fat tissue and also due in part to lifestyles ${ }^{36}$. Subjects supplemented with vitamin D in the reported studies maintained near optimal levels of serum 25(OH)D (Figure 2), despite the concern of severe vitamin D deficiency following bariatric surgery ${ }^{1524,37-39}$. While the cut-off for an optimal level of 25(OH)D varies from 20 to 30 $\mathrm{ng} / \mathrm{mL}$ by the Institute of Medicine and the 2011 Endocrine Society ${ }^{40}$, respectively, the levels of 25(OH)D in patients following RYGB surgery were all above $20 \mathrm{ng} / \mathrm{mL}$ except for one study ${ }^{41,42}$ (Figure 2a). From these studies, one may reconcile that intestinal calcium absorption and secondary PTH stimulation may not be totally dependent on vitamin D status.

In contrast, serum PTH has been shown to be overall persistently high normal or elevated following bariatric surgery ${ }^{15}$ (Figure $2 \mathrm{~b}$ ) and is responsible for an increase in bone turnover, and 
decrease bone strength in this population. The significance of PTH in alterations in bone strength was supported in a study of 22 women who underwent RYGB using HR-pQCT to determine the microfinite element of the bone $\mathrm{e}^{20}$. The results of this study indicated no alteration in trabecular bone, but significant impairment in cortical bone as manifested by prominent changes in the tibial cortical area, total density, cortical density, and cortical thickness ${ }^{20}$.

Role of Gastrointestinal Peptides in Bone Metabolism

Ghrelin is a peptide produced by the stomach fundus, which induces hunger in humans. Initial studies showed significant fall in ghrelin following $\mathrm{RYGB}^{43}$. However, since then, inconclusive data were reported following $\mathrm{RYGB}^{44}$. In a prospective double blind study comparing RYGB and SG, it was shown that ghrelin levels were significantly suppressed postparandially in SG, while there was no change in $\mathrm{RYGB}^{45}$. It has been shown that ghrelin in vitro increases osteoblastic cell proliferation and differentiation ${ }^{46}$. However, the in vivo effects on BMD using DEXA have been contradictory ${ }^{47}$.

Glucagon-like peptides (GLP-1 and GLP-2) are secreted postprandially by the intestinal Lcells $^{48}$. The serum levels of these peptides increases significantly after RYGB procedures. In only one study, it has been demonstrated that administration of GLP-1 is associated with a rise in $\mathrm{BMD}^{49}$.

\section{Prevalence of Kidney Stone Formation Following Bariatric Surgery}

Since abandonment of the jejunoileal bypass, it was hoped that the prevalence of kidney stone disease following modern bariatric surgery would be low. This was based upon the assumption that by leaving the ileum in place, intestinal fat malabsorption would be averted, limiting oxalate absorption and consequently hyperoxaluria. An initial report using data from a national private insurance claim database demonstrated among a large cohort consisting of 4,690 patients following RYGB, a significantly higher prevalence of kidney stones of $7.5 \%$ compared with $4.6 \%$ in obese controls ${ }^{50}$. The result of this study was later supported by another cross-sectional study of 762 patients from MN following bariatric surgery matched with obese controls who did not undergo surgery. More than $2 / 3$ of those treated in this study underwent RYGB with the remaining treatments consisting of other malabsorptive or restrictive operations ${ }^{51}$. Although prevalence of kidney stone episodes were similar between the two populations at the baseline, following RYGB the incidence of kidney stones more than doubled (11\%) compared with obese non-surgical patients $(4.3 \%)$. 
Unlike RYGB, the incidence of kidney stones following restrictive surgeries has been found to be low. In one study of 201 patients following gastric-banding procedures, matched with 201 morbidly obese-control patients over 2.5 years showed a significantly lower rate of stone formation of $1.5 \%$ vs. $6 \%$, respectively ${ }^{52}$. Another retrospective study of 332 patients following AGB and 85 patients with SG over a 54 - month period, demonstrated a very low stone incidence in the two cohorts ${ }^{51,53}$. Within the AGB cohort, a person-time incidence rate of 3.40 stone diagnoses per 1000 person-years, however, within the SG group a person-time incidence rate of 5.25 stone diagnosis per 1000 person - years was found ${ }^{53}$. These results highlight a much lower incidence of kidney stones following restrictive bariatric procedures compared to RYGB ${ }^{50,51}$ (Table 1).

\section{Pathophysiologic Mechanisms of Kidney Stone Formation Following Bariatric Surgery}

The underlying pathophysiologic mechanisms of kidney stone formation following bariatric surgery are complex and diverse, including hyperoxaluria, hypocitraturia, and abnormally acid urine increasing the risk for kidney stone formation.

\section{Role of High Urinary Oxalate following RYGB}

A high incidence of hyperoxaluria has been reported among $2 / 3$ of patients with kidney stones who have undergone $\mathrm{RYGB}^{54-59}$. The onset of development of hyperoxaluria varies and may occur either early or late following bariatric surgery, depending on the type of surgical procedure, the differences in dietary intake and the patient's health status ${ }^{57,58}$. However, urinary oxalate in the MN cohort was shown to increase over time in all patients following RYGB, with a more significant rise in those who developed kidney stones ${ }^{51}$. Similarly, calcium oxalate supersaturation was highest in the post-bariatric surgery patients who developed kidney stones. Consequently, the incidence of calcium oxalate stones following bariatric surgery increased while the incidence of stones with hydroxyapatite, struvite and uric acid compositions did not change.

Oxalate homeostasis is maintained through hepatic oxalate synthesis, dietary oxalate intake, intestinal absorption, and renal excretion ${ }^{60,61}$. The underlying pathophysiologic mechanism of hyperoxaluria has not been fully understood. Increased fecal fat content has been shown in only one study of 11 patients following RYGB. Intestinal fat malabsorption in this study was associated with the rise of plasma concentration of oxalate and thereby significantly elevated urinary calcium oxalate supersaturation ${ }^{61}$. From this finding, it was suggested that (1) 
complexation of unabsorbed fatty acids to calcium and magnesium in the intestinal lumen increases intestinal oxalate content and absorption (Figure 3). Validity of this scheme has been confirmed with oral oxalate load following bariatric surgery, showing an increase in urinary oxalate excretion 2-4 hours after oxalate $\operatorname{load}^{18,62}$. (2) It has been suggested but not validated that alterations in intestinal microbial flora following bariatric surgery could potentially modify the colonization of lower intestinal flora with respect to oxalobacter formigenes, which are known to degrade luminal oxalate ${ }^{63}$. (3) Yet, another pathway has been suggested to be due to increased permeability of the colonic mucosa epithelial cells as a consequence of exposure to unconjugated bile acids and long-chain fatty acids following RYGB ${ }^{64}$. Hyperoxaluria and kidney stone formation following restrictive bariatric surgery has not been significant ${ }^{65,66}$.

Role of Hypocitraturia following RYGB

Hypocitraturia commonly occurrs, but not for all patients following RYGB ${ }^{54-57,59}$. The prevalence varies from $24-63 \% \%^{36,56,58,62}$. Hypocitraturia is usually detected in metabolic acidosis ${ }^{67}$. Citrate plays an important inhibitory role against calcium oxalate and calcium phosphate crystallization. The inhibitory action involves the formation of soluble complexes with calcium, which reduces the urinary supersaturation. Citrate also exerts direct inhibitory effects against calcium oxalate crystallization processes ${ }^{68,69}$. One distinction in the hypocitraturic population is the absence of overt metabolic acidosis which may be attenuated implying participation of bone in the buffering of excessive acid load imposed by intestinal fluid loss ${ }^{67}$.

Role of Low Urinary Volume, Acidic Urine $\mathrm{pH}$ and Urinary Calcium Following RYGB Procedure

Due to a limited gastric pouch reservoir, low urinary volume is commonly detected in most of the bariatric population ${ }^{56-58}$. In two studies, acidic urine $\mathrm{pH}$ has been shown, but not uniformly, following RYGB, accompanied with supersaturation of undissociated uric acid ${ }^{56}$.

Hypocalciuria is frequently detected following RYGB, which plays a protective role against calcium oxalate crystallization by overriding the effect of hypocitraturia and hyperoxaluria $^{18,54,56,57,65}$. The underlying mechanism of hypocalciuria has been linked to impaired intestinal calcium absorption ${ }^{70}$.

Potential Unified Treatment Approach towards Bone Disease and Kidney Stone Formation Following Bariatric Surgery 
Given concern with nutritional deficiencies and impaired intestinal calcium absorption, the American Association of Clinical Endocrinologist, The Obesity Society, The American Society of Metabolic and Bariatric Surgery have all recommended calcium supplementation in this population $^{71}$. These guidelines include daily calcium supplementation of 1,200 - 2,000 mg as well as 50,000 IU of ergocalciferol once or twice a week and a higher dose of 50,000 - 150,000 IU per day for those subjects with severe vitamin D deficiency.

These societies specifically recommend that this population be supplemented with calcium citrate tablets due to its high intestinal bioavailability, based on study of post-menopausal women comparing the tablet formulation of calcium citrate and calcium carbonate ${ }^{72}$. However, it was shown that a single dose of calcium citrate in tablet form was not effective in suppressing PTH secretion in this population ${ }^{73,74}$. In contrast, administration of a single dose of pre-solubilized effervescent (liquid) potassium calcium citrate (PCC) conferred bioavailable calcium and was effective in inhibiting PTH secretion ${ }^{74}$. The pre-solubilized effervescent PCC supplementation is novel since it may reverse the pathophysiologic derangements operative for the bone loss and kidney stone formation (Figure 3).

A randomized, placebo controlled cross-over study in 24 patients following $\mathrm{RYGB}^{75}$ demonstrated that PCC significantly inhibits bone turnover by lowering PTH secretion (Figure 4). Additionally, treatment with PCC conferred an alkali load resulting in increased urinary $\mathrm{pH}$ and citrate, commensurate with attenuating urinary calcium excretion. These changes were accompanied with inhibition against calcium oxalate crystal agglomerations and reduction in urinary supersaturation of uric acid. Future long-term studies are needed to support the clinical efficacy of this medication against bone fractures and kidney stone incidence in this population.

Bisphosphonates are used as the first drug of choice in the treatment of senile osteoporosis. At present time there is not a report of use of these drugs following bariatric surgery. However, bisphosphonates have been used following gastric bypass surgery in patients with gastric cancer $^{76}$. In a study of 13 patients with gastric cancer who developed progressive bone loss with severe osteopenia unresponsive to vitamin D treatment, 2 years of alendronate improved BMD significantly. In a rat model of gastrectomy and gastric bypass induced osteoporosis/osteomalacia, treatment with oral bisphosphonate showed improvement in bone density and biochemical markers of bone turnover ${ }^{77}$. However, there is concern with the use of this drug following bariatric surgery due to underlying intestinal calcium malabsorption which 
potentially increases the risk for severe hypocalcemia in this population ${ }^{78}$. Also, the risk of GI erosions and ulcerations in this population could be increased due to reduced GI surface area as well as reduced absorption of oral bisphosphonates.

\section{Conclusion}

Bariatric surgery has been demonstrated to diminish cardiovascular risks, improve type 2 diabetes and reduce all causes of mortality in morbidly obese patients ${ }^{3,4}$, with an enormous impact on the health and the economy of the nation. However, it has emerged that it carries a high risk of bone fracture and kidney stones ${ }^{7,50,51}$. The impact of sleeve gastrectomy, a newly popular procedure, on the development of bone and kidney stone disease has not been fully explored. Therefore, it is crucial that this population receives prophylactic measures to avoid these complications. Treatment with PCC appears to be rational since it may avert both the skeletal and kidney stone complications in this population. However, the potential beneficial effects of this treatment should be tested in future controlled studies exploring kidney stone and bone fracture incidence.

\section{Acknowledgements}

The authors acknowledge Ms. Valeria Rodela for her role in the preparation of this manuscript. . The authors were supported by the National Institute of Health (R01 DK081423, RO1 DK081423-06), and ONR Award N00014-11-1-0203-03. 


\section{References}

1. Flegal KM, Carroll MD, Kit BK, Ogden CL. Prevalence of Obesity and Trends in the Distribution of Body Mass Index among Us Adults, 1999-2010. JAMA. 2012;307(5):491-497. http://dx.doi.org/10.1001/jama.2012.39

2. Ogden $\mathrm{CL}$, Carroll MD, Kit BK, Flegal KM. Prevalence of Childhood and Adult Obesity in the United States, 2011-2012. JAMA. 2014;311(8):806-814.

http://dx.doi.org/10.1001/jama.2014.732

3. Arterburn DE, Olsen MK, Smith VA, et al. Association between Bariatric Surgery and Long-Term Survival. JAMA. 2015;313(1):62-70. http://dx.doi.org/10.1001/jama.2014.16968

4. Chang SH, Stoll CR, Song J, Varela JE, Eagon CJ, Colditz GA. The Effectiveness and Risks of Bariatric Surgery: An Updated Systematic Review and Meta-Analysis, 2003-2012. JAMA Surg. 2014;149(3):275-287. http://dx.doi.org/10.1001/jamasurg.2013.3654

5. Reames BN, Finks JF, Bacal D, Carlin AM, Dimick JB. Changes in Bariatric Surgery Procedure Use in Michigan, 2006-2013. JAMA. 2014;312(9):959-961.

http://dx.doi.org/10.1001/jama.2014.7651

6. Lalmohamed A, de Vries F, Bazelier MT, et al. Risk of Fracture after Bariatric Surgery in the United Kingdom: Population Based, Retrospective Cohort Study. BMJ. 2012;345:e5085. http://dx.doi.org/10.1136/bmj.e5085

7. Nakamura KM, Haglind EG, Clowes JA, et al. Fracture Risk Following Bariatric Surgery: A Population-Based Study. Osteoporos Int. 2014;25(1):151-158. http://dx.doi.org/10.1007/s00198-013-2463-x

8. Ikramuddin S, Billington CJ, Lee WJ, et al. Roux-En-Y Gastric Bypass for Diabetes (the Diabetes Surgery Study): 2-Year Outcomes of a 5-Year, Randomised, Controlled Trial. Lancet Diabetes Endocrinol. 2015;3(6):413-422. http://dx.doi.org/10.1016/S2213-8587(15)00089-3

9. Goldner WS, O'Dorisio TM, Dillon JS, Mason EE. Severe Metabolic Bone Disease as a Long-Term Complication of Obesity Surgery. Obes Surg. 2002;12(5):685-692. http://dx.doi.org/10.1381/096089202321019693

10. von Mach MA, Stoeckli R, Bilz S, Kraenzlin M, Langer I, Keller U. Changes in Bone Mineral Content after Surgical Treatment of Morbid Obesity. Metabolism. 2004;53(7):918-921. http://dx.doi.org/10.1016/i.metabol.2004.01.015

11. Carrasco F, Ruz M, Rojas P, et al. Changes in Bone Mineral Density, Body Composition and Adiponectin Levels in Morbidly Obese Patients after Bariatric Surgery. Obes Surg. 2009;19(1):4146. http://dx.doi.org/10.1007/s11695-008-9638-0

12. Casagrande DS, Repetto G, Mottin CC, et al. Changes in Bone Mineral Density in Women Following 1-Year Gastric Bypass Surgery. Obes Surg. 2012;22(8):1287-1292. http://dx.doi.org/10.1007/s11695-012-0687-z

13. Nogues X, Goday A, Pena MJ, et al. [Bone Mass Loss after Sleeve Gastrectomy: A Prospective Comparative Study with Gastric Bypass]. Cir Esp. 2010;88(2):103-109.

http://dx.doi.org/10.1016/i.ciresp.2010.04.008

14. Johnson JM, Maher JW, Samuel I, Heitshusen D, Doherty C, Downs RW. Effects of Gastric Bypass Procedures on Bone Mineral Density, Calcium, Parathyroid Hormone, and Vitamin D. J Gastrointest Surg. 2005;9(8):1106-1110. http://dx.doi.org/10.1016/j.gassur.2005.07.012

15. Coates PS, Fernstrom JD, Fernstrom MH, Schauer PR, Greenspan SL. Gastric Bypass Surgery for Morbid Obesity Leads to an Increase in Bone Turnover and a Decrease in Bone Mass. J Clin Endocrinol Metab. 2004;89(3):1061-1065. http://dx.doi.org/10.1210/jc.2003-031756 
16. Yu EW, Bouxsein ML, Roy AE, et al. Bone Loss after Bariatric Surgery: Discordant Results between Dxa and Qct Bone Density. J Bone Miner Res. 2014;29(3):542-550.

http://dx.doi.org/10.1002/ibmr.2063

17. Vilarrasa N, San Jose P, Garcia I, et al. Evaluation of Bone Mineral Density Loss in Morbidly Obese Women after Gastric Bypass: 3-Year Follow-Up. Obes Surg. 2011;21(4):465-472. http://dx.doi.org/10.1007/s11695-010-0338-1

18. Fleischer J, Stein EM, Bessler M, et al. The Decline in Hip Bone Density after Gastric Bypass Surgery Is Associated with Extent of Weight Loss. J Clin Endocrinol Metab. 2008;93(10):37353740. http://dx.doi.org/10.1210/jc.2008-0481

19. Carlin AM, Rao DS, Yager KM, Parikh NJ, Kapke A. Treatment of Vitamin D Depletion after RouxEn-Y Gastric Bypass: A Randomized Prospective Clinical Trial. Surg Obes Relat Dis. 2009;5(4):444449. http://dx.doi.org/10.1016/i.soard.2008.08.004

20. Stein EM, Carrelli A, Young P, et al. Bariatric Surgery Results in Cortical Bone Loss. $J$ Clin Endocrinol Metab. 2013;98(2):541-549. http://dx.doi.org/10.1210/ic.2012-2394

21. Vilarrasa N, Gomez JM, Elio I, et al. Evaluation of Bone Disease in Morbidly Obese Women after Gastric Bypass and Risk Factors Implicated in Bone Loss. Obes Surg. 2009;19(7):860-866. http://dx.doi.org/10.1007/s11695-009-9843-5

22. Pluskiewicz W, Buzga M, Holeczy P, Bortlik L, Smajstrla V, Adamczyk P. Bone Mineral Changes in Spine and Proximal Femur in Individual Obese Women after Laparoscopic Sleeve Gastrectomy: A Short-Term Study. Obes Surg. 2012;22(7):1068-1076. http://dx.doi.org/10.1007/s11695-012$\underline{0654-8}$

23. Ruiz-Tovar J, Oller I, Priego P, et al. Short- and Mid-Term Changes in Bone Mineral Density after Laparoscopic Sleeve Gastrectomy. Obes Surg. 2013;23(7):861-866. http://dx.doi.org/10.1007/s11695-013-0866-6

24. Yu EW, Bouxsein ML, Putman MS, et al. Two-Year Changes in Bone Density after Roux-En-Y Gastric Bypass Surgery. J Clin Endocrinol Metab. 2015;100(4):1452-1459. http://dx.doi.org/10.1210/ic.2014-4341

25. Nguyen NT, Nguyen B, Gebhart A, Hohmann S. Changes in the Makeup of Bariatric Surgery: A National Increase in Use of Laparoscopic Sleeve Gastrectomy. J Am Coll Surg. 2013;216(2):252257. http://dx.doi.org/10.1016/i.jamcollsurg.2012.10.003

26. Lazzati A, Guy-Lachuer R, Delaunay V, Szwarcensztein K, Azoulay D. Bariatric Surgery Trends in France: 2005-2011. Surg Obes Relat Dis. 2014;10(2):328-334. http://dx.doi.org/10.1016/i.soard.2013.07.015

27. Schoenau E, Frost HM. The "Muscle-Bone Unit" in Children and Adolescents. Calcif Tissue Int. 2002;70(5):405-407. http://dx.doi.org/10.1007/s00223-001-0048-8

28. Lin C, Jiang X, Dai Z, et al. Sclerostin Mediates Bone Response to Mechanical Unloading through Antagonizing Wnt/Beta-Catenin Signaling. J Bone Miner Res. 2009;24(10):1651-1661. http://dx.doi.org/10.1359/ibmr.090411

29. Li X, Ominsky MS, Warmington KS, et al. Sclerostin Antibody Treatment Increases Bone Formation, Bone Mass, and Bone Strength in a Rat Model of Postmenopausal Osteoporosis. J Bone Miner Res. 2009;24(4):578-588. http://dx.doi.org/10.1359/ibmr.081206

30. Wijenayaka AR, Kogawa M, Lim HP, Bonewald LF, Findlay DM, Atkins GJ. Sclerostin Stimulates Osteocyte Support of Osteoclast Activity by a Rankl-Dependent Pathway. PLoS One. 2011;6(10):e25900. http://dx.doi.org/10.1371/journal.pone.0025900

31. Muschitz C, Kocijan R, Marterer C, et al. Sclerostin Levels and Changes in Bone Metabolism after Bariatric Surgery. J Clin Endocrinol Metab. 2015;100(3):891-901.

http://dx.doi.org/10.1210/jc.2014-3367 
32. Schafer AL, Weaver CM, Black DM, et al. Intestinal Calcium Absorption Decreases Dramatically after Gastric Bypass Surgery Despite Optimization of Vitamin D Status. J Bone Miner Res. 2015. http://dx.doi.org/10.1002/ibmr.2467

33. Pak CY, Poindexter J, Finlayson B. A Model System for Assessing Physicochemical Factors Affecting Calcium Absorbability from the Intestinal Tract. J Bone Miner Res. 1989;4(1):119-127. http://dx.doi.org/10.1002/jbmr.5650040117

34. Stemmer K, Bielohuby M, Grayson BE, et al. Roux-En-Y Gastric Bypass Surgery but Not Vertical Sleeve Gastrectomy Decreases Bone Mass in Male Rats. Endocrinology. 2013;154(6):2015-2024. http://dx.doi.org/10.1210/en.2012-2130

35. Hey $\mathrm{H}$, Stokholm KH, Lund B, Lund B, Sorensen $\mathrm{OH}$. Vitamin D Deficiency in Obese Patients and Changes in Circulating Vitamin D Metabolites Following Jejunoileal Bypass. Int J Obes. 1982;6(5):473-479.

36. Sakhaee K. Bariatric Surgery and Effects on Calcium and Bone Metabolism. Clinical Reviews in Bone and Mineral Metabolism. 2014;12(4):240-251. http://dx.doi.org/10.1007/s12018-0139145-2

37. Ott MT, Fanti P, Malluche HH, et al. Biochemical Evidence of Metabolic Bone Disease in Women Following Roux-Y Gastric Bypass for Morbid Obesity. Obes Surg. 1992;2(4):341-348.

38. Heber D, Greenway FL, Kaplan LM, et al. Endocrine and Nutritional Management of the PostBariatric Surgery Patient: An Endocrine Society Clinical Practice Guideline. J Clin Endocrinol Metab. 2010;95(11):4823-4843. http://dx.doi.org/10.1210/jc.2009-2128

39. Slater GH, Ren CJ, Siegel N, et al. Serum Fat-Soluble Vitamin Deficiency and Abnormal Calcium Metabolism after Malabsorptive Bariatric Surgery. J Gastrointest Surg. 2004;8(1):48-55.

40. Fuleihan Gel H, Bouillon R, Clarke B, et al. Serum 25-Hydroxyvitamin D Levels: Variability, Knowledge Gaps, and the Concept of a Desirable Range. J Bone Miner Res. 2015;30(7):11191133. http://dx.doi.org/10.1002/ibmr.2536

41. Dawson-Hughes B, Heaney RP, Holick MF, Lips P, Meunier PJ, Vieth R. Estimates of Optimal Vitamin D Status. Osteoporos Int. 2005;16(7):713-716. http://dx.doi.org/10.1007/s00198-005$\underline{1867-7}$

42. Institute of Medicine Committee to Review Dietary Reference Intakes for Vitamin D, Calcium. The National Academies Collection: Reports Funded by National Institutes of Health. In: Ross AC, Taylor CL, Yaktine AL, Del Valle HB, eds. Dietary Reference Intakes for Calcium and Vitamin D. Washington (DC): National Academies Press (US), National Academy of Sciences.; 2011.

43. Cummings DE, Weigle DS, Frayo RS, et al. Plasma Ghrelin Levels after Diet-Induced Weight Loss or Gastric Bypass Surgery. N Eng/ J Med. 2002;346(21):1623-1630.

http://dx.doi.org/10.1056/NEJMoa012908

44. Pournaras DJ, le Roux CW. Ghrelin and Metabolic Surgery. Int J Pept. 2010;2010. http://dx.doi.org/10.1155/2010/217267

45. Karamanakos SN, Vagenas K, Kalfarentzos F, Alexandrides TK. Weight Loss, Appetite Suppression, and Changes in Fasting and Postprandial Ghrelin and Peptide-Yy Levels after RouxEn-Y Gastric Bypass and Sleeve Gastrectomy: A Prospective, Double Blind Study. Ann Surg. 2008;247(3):401-407. http://dx.doi.org/10.1097/SLA.0b013e318156f012

46. Maccarinelli G, Sibilia V, Torsello A, et al. Ghrelin Regulates Proliferation and Differentiation of Osteoblastic Cells. J Endocrinol. 2005;184(1):249-256. http://dx.doi.org/10.1677/joe.1.05837

47. Napoli N, Pedone C, Pozzilli P, et al. Effect of Ghrelin on Bone Mass Density: The Inchianti Study. Bone. 2011;49(2):257-263. http://dx.doi.org/10.1016/j.bone.2011.03.772

48. Bollag RJ, Zhong Q, Phillips P, et al. Osteoblast-Derived Cells Express Functional GlucoseDependent Insulinotropic Peptide Receptors. Endocrinology. 2000;141(3):1228-1235. http://dx.doi.org/10.1210/endo.141.3.7366 
49. Nuche-Berenguer B, Moreno $P$, Esbrit $P$, et al. Effect of Glp-1 Treatment on Bone Turnover in Normal, Type 2 Diabetic, and Insulin-Resistant States. Calcif Tissue Int. 2009;84(6):453-461. http://dx.doi.org/10.1007/s00223-009-9220-3

50. Matlaga BR, Shore AD, Magnuson T, Clark JM, Johns R, Makary MA. Effect of Gastric Bypass Surgery on Kidney Stone Disease. J Urol. 2009;181(6):2573-2577. http://dx.doi.org/10.1016/j.juro.2009.02.029

51. Lieske JC, Mehta RA, Milliner DS, Rule AD, Bergstralh EJ, Sarr MG. Kidney Stones Are Common after Bariatric Surgery. Kidney Int. 2015;87(4):839-845. http://dx.doi.org/10.1038/ki.2014.352

52. Semins MJ, Matlaga BR, Shore AD, et al. The Effect of Gastric Banding on Kidney Stone Disease. Urology. 2009;74(4):746-749. http://dx.doi.org/10.1016/i.urology.2009.04.093

53. Chen T, Godebu E, Horgan S, Mirheydar HS, Sur RL. The Effect of Restrictive Bariatric Surgery on Urolithiasis. J Endourol. 2013;27(2):242-244. http://dx.doi.org/10.1089/end.2012.0408

54. Sinha MK, Collazo-Clavell ML, Rule A, et al. Hyperoxaluric Nephrolithiasis Is a Complication of Roux-En-Y Gastric Bypass Surgery. Kidney Int. 2007;72(1):100-107. http://dx.doi.org/10.1038/sj.ki.5002194

55. Asplin JR, Coe FL. Hyperoxaluria in Kidney Stone Formers Treated with Modern Bariatric Surgery. J Urol. 2007;177(2):565-569. http://dx.doi.org/10.1016/j.juro.2006.09.033

56. Park AM, Storm DW, Fulmer BR, Still CD, Wood GC, Hartle JE, 2nd. A Prospective Study of Risk Factors for Nephrolithiasis after Roux-En-Y Gastric Bypass Surgery. J Urol. 2009;182(5):23342339. http://dx.doi.org/10.1016/j.juro.2009.07.044

57. Duffey BG, Pedro RN, Makhlouf A, et al. Roux-En-Y Gastric Bypass Is Associated with Early Increased Risk Factors for Development of Calcium Oxalate Nephrolithiasis. J Am Coll Surg. 2008;206(3):1145-1153. http://dx.doi.org/10.1016/j.jamcollsurg.2008.01.015

58. Duffey BG, Alanee S, Pedro RN, et al. Hyperoxaluria Is a Long-Term Consequence of Roux-En-Y Gastric Bypass: A 2-Year Prospective Longitudinal Study. J Am Coll Surg. 2010;211(1):8-15. http://dx.doi.org/10.1016/j.jamcollsurg.2010.03.007

59. Patel BN, Passman CM, Fernandez A, et al. Prevalence of Hyperoxaluria after Bariatric Surgery. J Urol. 2009;181(1):161-166. http://dx.doi.org/10.1016/j.juro.2008.09.028

60. Sakhaee K. Recent Advances in the Pathophysiology of Nephrolithiasis. Kidney Int. 2009;75(6):585-595. http://dx.doi.org/10.1038/ki.2008.626

61. Kumar R, Lieske JC, Collazo-Clavell ML, et al. Fat Malabsorption and Increased Intestinal Oxalate Absorption Are Common after Roux-En-Y Gastric Bypass Surgery. Surgery. 2011;149(5):654-661. http://dx.doi.org/10.1016/i.surg.2010.11.015

62. Froeder L, Arasaki CH, Malheiros CA, Baxmann AC, Heilberg IP. Response to Dietary Oxalate after Bariatric Surgery. Clin J Am Soc Nephrol. 2012;7(12):2033-2040.

http://dx.doi.org/10.2215/CJN.02560312

63. Kaufman DW, Kelly JP, Curhan GC, et al. Oxalobacter Formigenes May Reduce the Risk of Calcium Oxalate Kidney Stones. J Am Soc Nephrol. 2008;19(6):1197-1203. http://dx.doi.org/10.1681/ASN.2007101058

64. Dobbins JW, Binder HJ. Effect of Bile Salts and Fatty Acids on the Colonic Absorption of Oxalate. Gastroenterology. 1976;70(6):1096-1100. http://dx.doi.org/S0016508576001376 [pii]

65. Penniston KL, Kaplon DM, Gould JC, Nakada SY. Gastric Band Placement for Obesity Is Not Associated with Increased Urinary Risk of Urolithiasis Compared to Bypass. J Urol. 2009;182(5):2340-2346. http://dx.doi.org/10.1016/i.juro.2009.07.041

66. Semins MJ, Asplin JR, Steele K, et al. The Effect of Restrictive Bariatric Surgery on Urinary Stone Risk Factors. Urology. 2010;76(4):826-829. http://dx.doi.org/10.1016/i.urology.2010.01.037

67. Alpern RJ, Sakhaee K. The Clinical Spectrum of Chronic Metabolic Acidosis: Homeostatic Mechanisms Produce Significant Morbidity. Am J Kidney Dis. 1997;29(2):291-302. 
68. Kok DJ, Papapoulos SE, Bijvoet OL. Excessive Crystal Agglomeration with Low Citrate Excretion in Recurrent Stone-Formers. Lancet. 1986;1(8489):1056-1058.

69. Sakhaee K, Maalouf NM, Sinnott B. Clinical Review. Kidney Stones 2012: Pathogenesis, Diagnosis, and Management. J Clin Endocrinol Metab. 2012;97(6):1847-1860. http://dx.doi.org/10.1210/jc.2011-3492

70. Riedt CS, Brolin RE, Sherrell RM, Field MP, Shapses SA. True Fractional Calcium Absorption Is Decreased after Roux-En-Y Gastric Bypass Surgery. Obesity (Silver Spring). 2006;14(11):19401948. http://dx.doi.org/10.1038/oby.2006.226

71. Mechanick JI, Kushner RF, Sugerman HJ, et al. American Association of Clinical Endocrinologists, the Obesity Society, and American Society for Metabolic \& Bariatric Surgery Medical Guidelines for Clinical Practice for the Perioperative Nutritional, Metabolic, and Nonsurgical Support of the Bariatric Surgery Patient. Surg Obes Relat Dis. 2008;4(5 Suppl):S109-184.

http://dx.doi.org/10.1016/j.soard.2008.08.009

72. Heller HJ, Greer LG, Haynes SD, Poindexter JR, Pak CY. Pharmacokinetic and Pharmacodynamic Comparison of Two Calcium Supplements in Postmenopausal Women. J Clin Pharmacol. 2000;40(11):1237-1244.

73. Tondapu P, Provost D, Adams-Huet B, Sims T, Chang C, Sakhaee K. Comparison of the Absorption of Calcium Carbonate and Calcium Citrate after Roux-En-Y Gastric Bypass. Obes Surg. 2009;19(9):1256-1261. http://dx.doi.org/10.1007/s11695-009-9850-6

74. Sakhaee K, Pak C. Superior Calcium Bioavailability of Effervescent Potassium Calcium Citrate over Tablet Formulation of Calcium Citrate after Roux-En-Y Gastric Bypass. Surg Obes Relat Dis. 2013;9(5):743-748. http://dx.doi.org/10.1016/i.soard.2011.11.011

75. Sakhaee K, Griffith C, Pak CY. Biochemical Control of Bone Loss and Stone-Forming Propensity by Potassium-Calcium Citrate after Bariatric Surgery. Surg Obes Relat Dis. 2012;8(1):67-72. http://dx.doi.org/10.1016/i.soard.2011.05.001

76. Suzuki Y, Ishibashi Y, Omura N, et al. Alendronate Improves Vitamin D-Resistant Osteopenia Triggered by Gastrectomy in Patients with Gastric Cancer Followed Long Term. J Gastrointest Surg. 2005;9(7):955-960. http://dx.doi.org/10.1016/j.gassur.2005.04.020

77. Suzuki Y, Fukushima S, Iwai T, et al. Bisphosphonate Incadronate Prevents Total GastrectomyInduced Osteopenia in Rats. Bone. 2004;35(6):1346-1352. http://dx.doi.org/10.1016/j.bone.2004.09.006

78. Rosen CJ, Brown S. Severe Hypocalcemia after Intravenous Bisphosphonate Therapy in Occult Vitamin D Deficiency. N Eng/ J Med. 2003;348(15):1503-1504. http://dx.doi.org/10.1056/NEJM200304103481521 


\section{Figure Legends}

Figure 1. Bone mineral density changes at spine (Figure 1a) and hip (Figure 1b) following RYGB. Adapted from Yu, JBMR, 2014. Needs permission.

Figure 2. Serum 25(OH)D (Figure 2a) and serum PTH (Figure 2b) following RYGB and SG.

Figure 3. Complications of bariatric surgery: Intestinal Calcium Malabsorption and Secondary PTH Stimulation, GI Alkali Loss, Intestinal Fat Malabsorption, and Increased Intestinal Oxalate Absorption.

Figure 4. Effects of PCC on serum $\mathrm{Ca}, \mathrm{PTH}$, bone turnover markers and saturation indices. Data is presented as mean \pm standard deviation, except for calcium oxalate agglomeration inhibition in which individual data is shown. Sakhaee, Surg \& Obes Related Dis, 2012. Needs permission. 
Table 1.

\begin{tabular}{|c|c|c|c|c|c|c|c|c|}
\hline & \multicolumn{2}{|c|}{ Matlaga et al } & \multicolumn{2}{|c|}{ Lieske et al } & \multicolumn{2}{|c|}{ Semins et al } & \multicolumn{2}{|c|}{ Chen et al } \\
\hline & Surgery & Control & Surgery & Control & Surgery & Control & GB & SG \\
\hline $\mathrm{N}$ & 4639 & 4639 & 762 & 759 & 201 & 201 & 332 & 85 \\
\hline Age, years & $44.6 \pm 9.5$ & $45.0 \pm 10.2$ & $44.7 \pm 11.2$ & $44.7 \pm 11.2$ & $46.3 \pm 9.4$ & $46.5 \pm 10.1$ & NA & NA \\
\hline Gender, $\%$ male / $\%$ female & $19.5 / 80.5$ & $19.5 / 80.5$ & $19.4 / 80.6$ & $19.4 / 80.6$ & $17.4 / 82.6$ & $17.4 / 82.6$ & $20.0 / 80.0^{\mathrm{a}}$ & \\
\hline Pre-operative BMI, kg/m2 & $>35$ & $>35$ & $46.7 \pm 7.9$ & $46.7 \pm 7.8$ & NA & $>35$ & NA & NA \\
\hline \multicolumn{9}{|l|}{ Type of Surgery } \\
\hline RYGB & 4639 & & 646 & & 0 & & 0 & 0 \\
\hline Duodenal switch & 0 & & 50 & & 0 & & 0 & 0 \\
\hline Gastric banding & 0 & & 43 & & 201 & & 332 & 0 \\
\hline Sleeve gastrectomy & 0 & & 13 & & 0 & & 0 & 85 \\
\hline Duration of follow-up, years & 4.6 & 4.1 & 6.9 & 7.0 & 2.3 & 2.2 & 3.5 & 2.2 \\
\hline person-years & 21362 & 19031 & 5258 & 5313 & 458 & 451 & 1178 & 190 \\
\hline \multicolumn{9}{|l|}{ Nephrolithiasis } \\
\hline Prevalence at baseline, $\%$ & excluded & & 4.3 & 4.0 & excluded & & excluded & \\
\hline Incidence during follow-up, $\%$ & 7.65 & 4.63 & 11.1 & 4.3 & 1.49 & 5.97 & 1.2 & 1.18 \\
\hline Incidence / 1000 patient-years & 0.36 & 0.24 & 2.11 & 0.81 & 3.25 & 13.24 & 3.4 & 5.25 \\
\hline
\end{tabular}

$\mathrm{NA}=$ Not available; ${ }^{\mathrm{a}}$ Approximate 


\section{Figures}

Figure 1

A

$\begin{array}{lllllllllllll}14 & 30 & 22 & 62 & 60 & 30 & 15 & 14 & 7 & 22 & 42 & 4 & \text { Study Size }\end{array}$

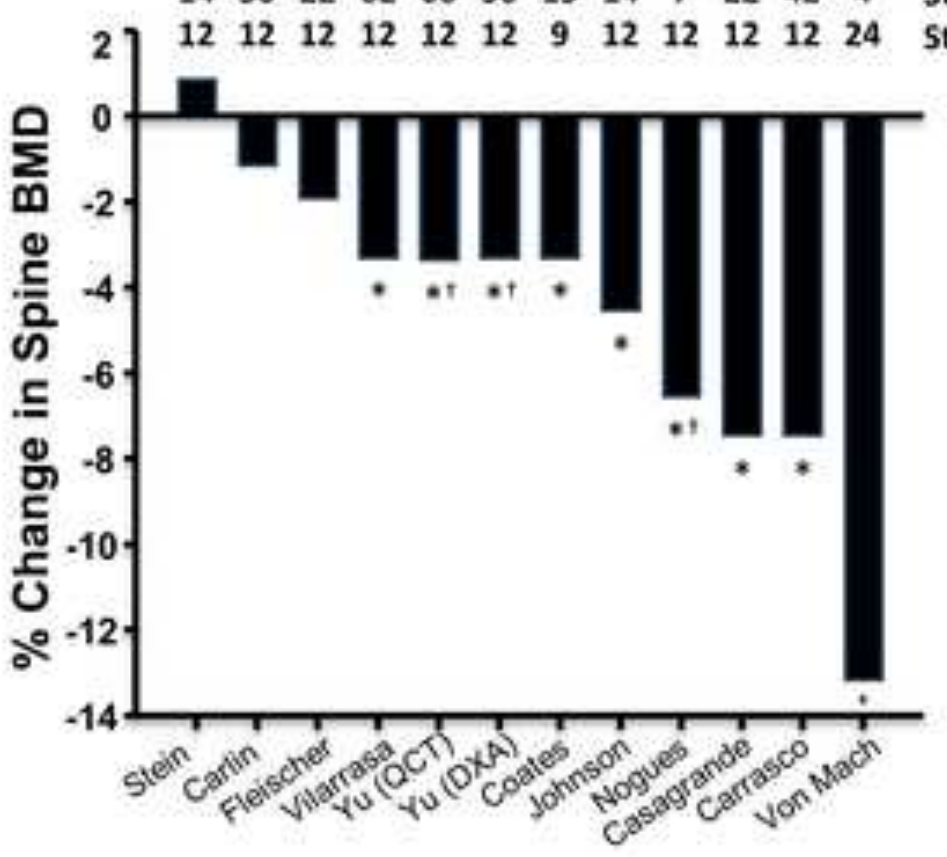

- Significantly different campared with baseline

+ Significantly different compared with control group
B

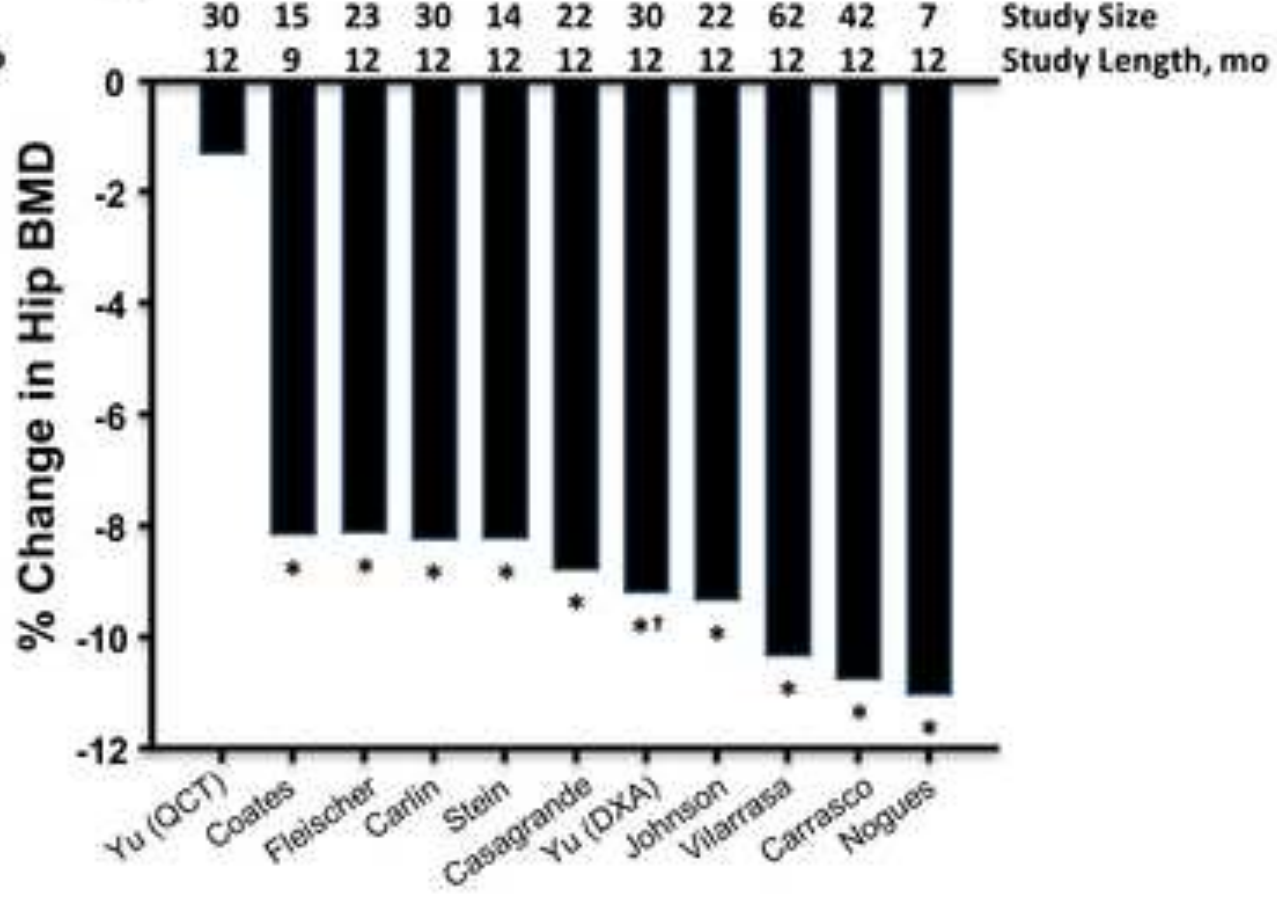

Adapted from Yu, JBMR, 2014 
A

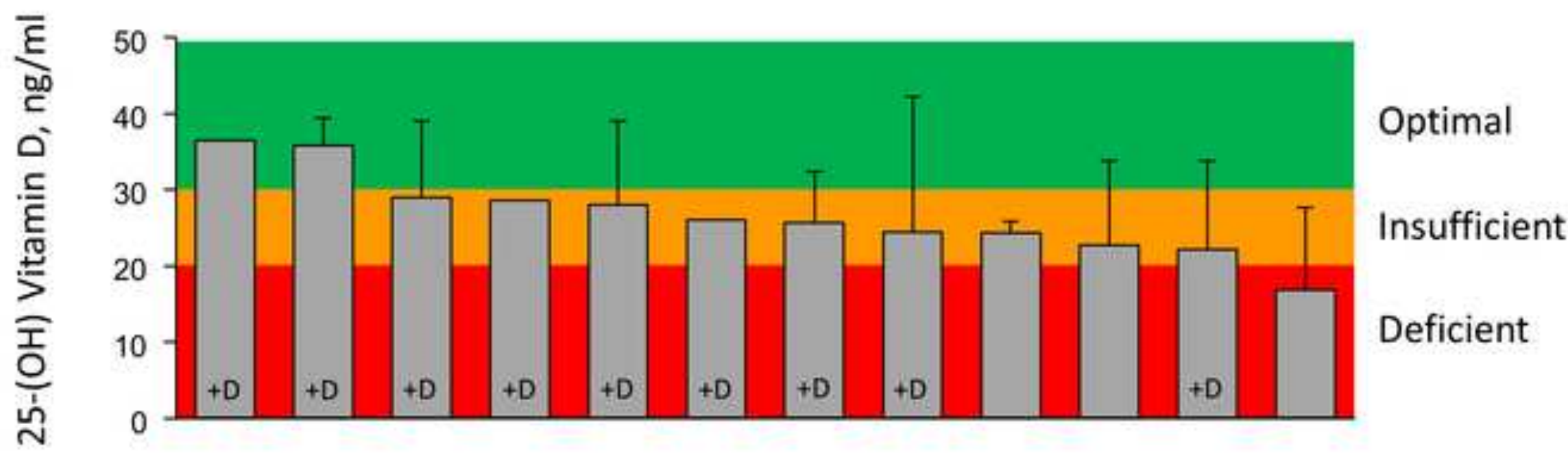

B

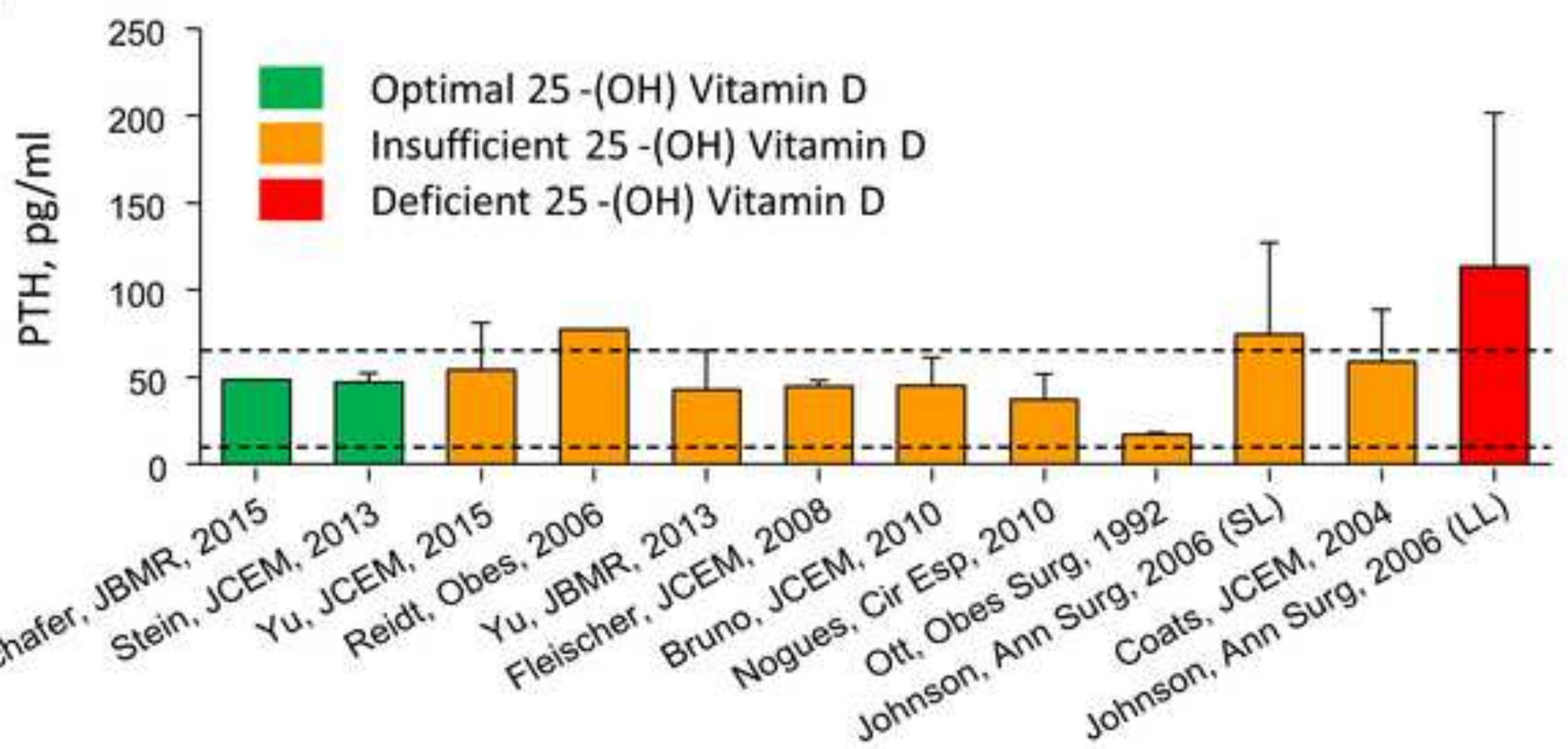




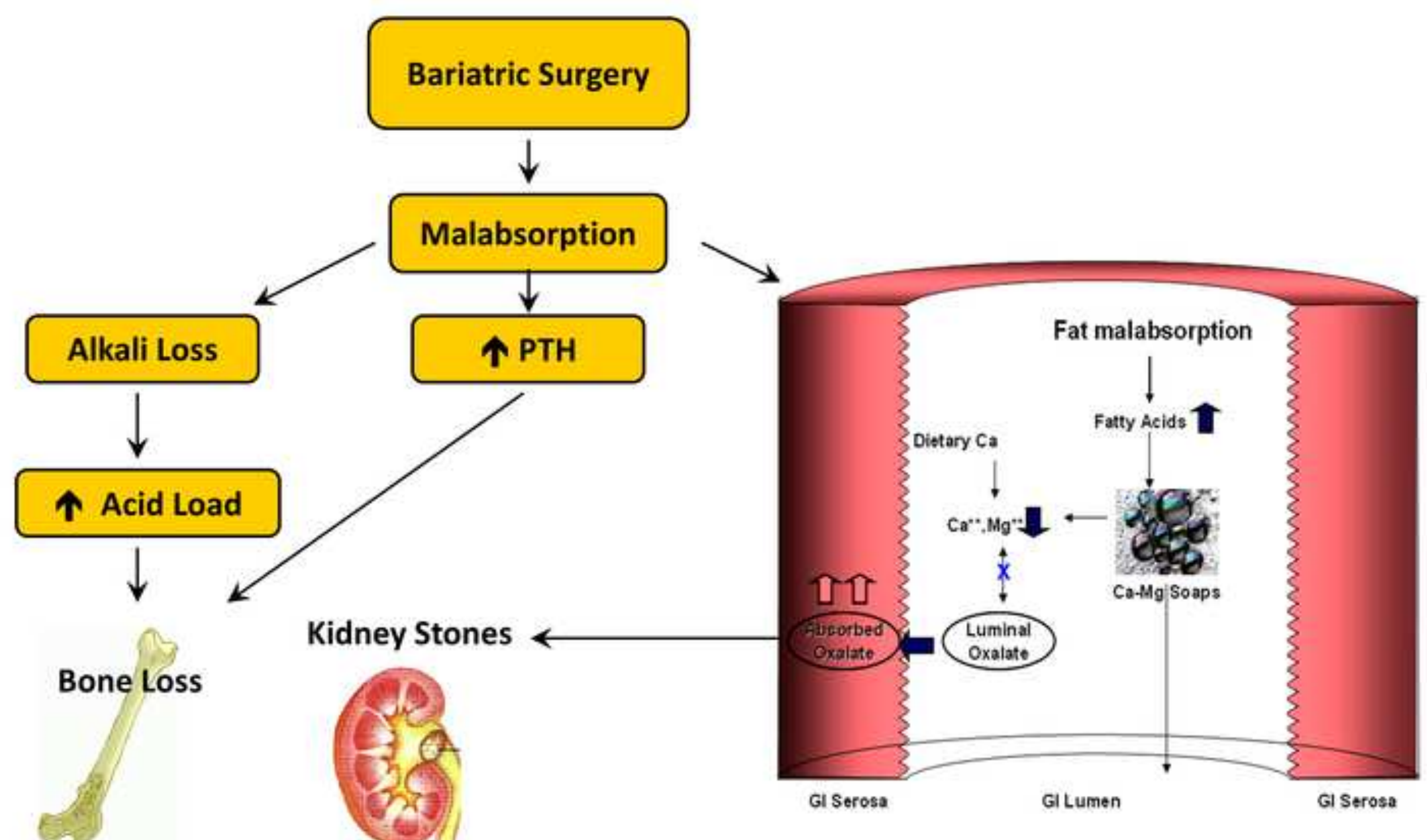



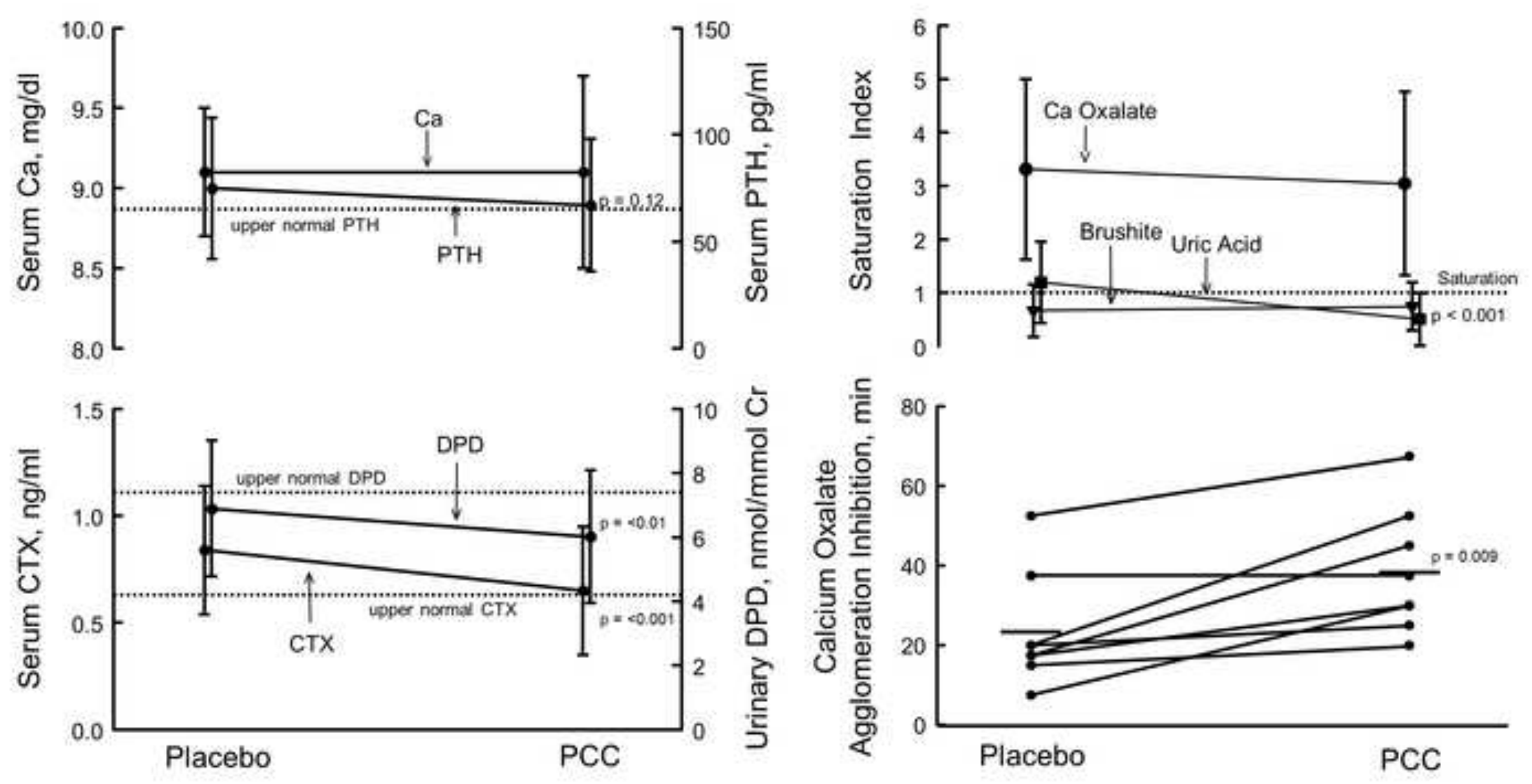

Sakhaee \& Pak, Surg Obes Related Dis, 2012 